\title{
Right temporofrontal cortex as critical locus for the ecphory of old episodic memories
}

\author{
P Calabrese, H J Markowitsch, H F Durwen, H Widlitzek, M Haupts, B Holinka, \\ W Gehlen
}

\begin{abstract}
A 54 year old patient of average intelligence with a severe and enduring loss of old autobiographical memories after herpes simplex type 1 infection is described. She was tested with a comprehensive neuropsychological battery two years after the infection. Special emphasis was laid on examining different aspects of retrograde memory. The neurological examination involved MRI and SPECT. Brain damage was found mainly in the right temporofrontal region, but minor left sided damage to this region seems possible. The patient was in the normal or slightly subnormal range for all tested anterograde memory functions, but manifested severe retrograde memory deficits with respect to episodic old memories and more moderate deficits in tests of general knowledge (semantic old memories). It is concluded that the ecphory of old autobiographical memories relies heavily on an activation of the right lateral temporofrontal junction area, but that probably only some complementary left hemispheric damage to these regions will lead to major and persistent retrograde amnesia. Alternatively, the disconnection between major prefrontal and posterior cortical regions may provide a basis for retrograde amnesia.
\end{abstract}

$(\Im$ Neurol Neurosurg Psychiatry 1996;61:304-310)

Neurological

University Hospital,

Bochum-Langendreer, Germany

$P$ Calabrese

H F Durwen

M Haupts

B Holinka

W Gehlen

Physiological

Psychology, University of Bielefeld, Bielefeld, Germany

H J Markowitsch

Institute of Radiology,

University Hospital,

Bochum-Langendreer,

Germany

$\mathrm{H}$ Widlitzek

Correspondence to:

Dr Hans J Markowitsch,

Physiological Psychology,

University of Bielefeld, PO

Box 1001 31, D-33501

Bielefeld, Germany.

Received 8 December 1995

and in revised form

12 March 1996

Accepted 12 March 1996
Keywords: retrograde amnesia; memory; medial temporal lobe

In recent years evidence for an anatomical dissociation of anterograde and retrograde memory functions has accumulated. ${ }^{1-10}$ While the essential bottleneck structures, relevant for information transmission for long term storage have largely been established, ${ }^{11}$ there is still a substantial lack of consistency with respect to the brain regions implicated in focal retrograde amnesia. ${ }^{5-7} 1213$ The structures most often implicated in focal retrograde amnesia are situated in the prefrontal and temporal cortex, with some authors emphasising the importance of one structure or the other, and other authors assuming that only the combined and bilateral damage of portions of both frontal and temporal regions are necessary for the appearance of a fullblown retrograde amnesic syndrome. ${ }^{13}$ This inconsistency is enhanced by the currently widely accepted dissociation of different memory systems of which the episodic semantic dis- tinction is the most common one. ${ }^{14}$ Episodic memories are those which can be traced back with respect to time and locus, whereas semantic memories signify those of a general nature (knowledge of the world).

In a recent review, ${ }^{13}$ the hypothesis that the combined action of inferolateral prefrontal and anterolateral temporal cortices is necessary for the retrieval of long term memory, was advanced on the basis of a comparison of several case reports and data on memory retrieval in normal subjects obtained with PET. Furthermore, it was speculated that these regions in the right hemisphere would primarily be engaged in triggering episodic old memories, whereas the same regions of the left hemisphere would be involved in retrieving information from the knowledge system. ${ }^{13}$ We report the case of a patient who fits into this proposed scheme by being selectively retrogradely amnesic in the episodic memory domain and having a SPECT documented hypoperfusion in the right temporo frontal junction area.

\section{Case report}

The patient, a 54 year old right handed woman had been admitted three years ago to the hospital as an emergency case with herpes simplex type 1 meningoencephalitis.

\section{NEUROLOGICAL AND NEURORADIOLOGICAL}

EVALUATION

The history of her illness started with complaints of nausea and tiredness one week before admission. Two days before admission she developed high fever with temperatures up to $39.8^{\circ} \mathrm{C}$, complained about increasing headaches, and became more and more disoriented. Intermittently she was unable to recognise her family and showed signs of visual hallucinations for short periods. Finally she drifted into a state of severe drowsiness.

Her previous medical history involved left sided mastectomy for breast cancer as well as a hysterectomy, both about 10 years earlier. The family history of the patient disclosed no events with neurological, psychiatric, or other relevance.

On admission she was in a severe drowsy state, but could be awakened by painful external stimuli. She was then able to answer simple questions with yes or no, and to carry out simple movements to verbal command. A more complex form of communication, however, was not possible. Further neurological examination disclosed soft meningeal signs as well as a discrete to moderate left sided hemiparesis including 
Figure 1 General T1 weighted MRI after $G d$ $D T P A$ contrast injection performed about three years after infection. Coronal sections from top left to bottom right demonstrate the principal loci of brain damage in the right inferior lateral prefrontal cortex (top left), the right temporopolar cortex (top right), and the right anterior temporal lobe (bottom left and right).

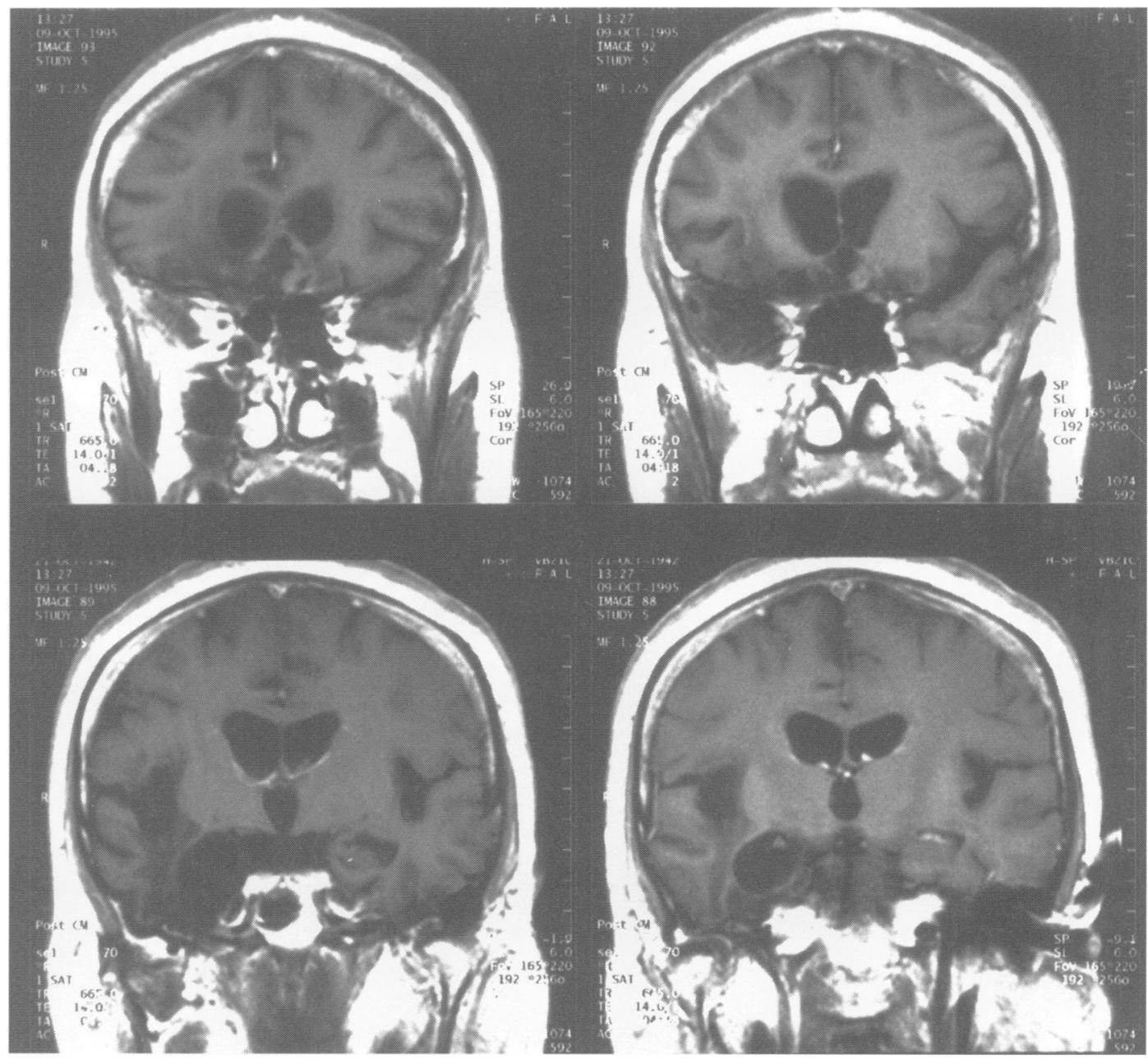

bracchiofacial hemiparesis. Babinski's sign was positive and the muscular reflexes were raised on the left. Reactions to painful stimuli could be elicited from both sides to the same extent.

An initial cranial CT showed a hypoattenuation in both hemispheres with a discrete right sided accentuation, predominantly in the frontotemporal region. After injection of an intravenous contrast a diffuse inhomogeneous enhancement was seen in the areas affected. A cranial CT control, one month later, was normal.

The first MRI was performed somewhat less than three months after onset of the disease.

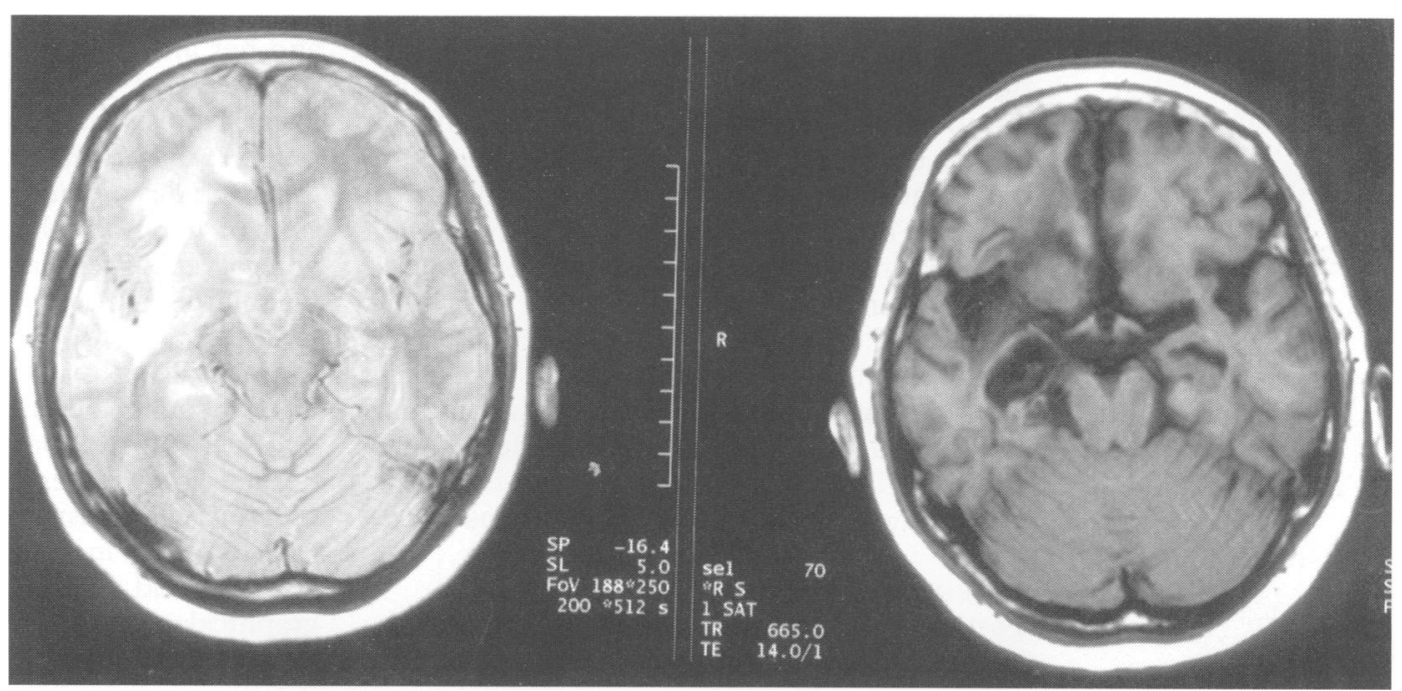

There was low signal intensity on $\mathrm{T} 1$ weighted images and high signal intensity on $\mathrm{T} 2$ weighted images in the right frontotemporal region with the maximum in the right temporal lobe, and, in addition, there was evidence of a circumscribed cystic substance loss in the right temporal and frontobasal brain regions. The damage included anterior portions of the right amygdalohippocampal region and affected in particular the region of the pathway of the right ventral branch of the uncinate fascicle (fig 1 in Markowitsch ${ }^{13}$ ). Results from a second MRI, performed about three years later, confirm those of the first (figs 1 and 2). Minor left sided
Figure 2 Axial proton density images through the centre of the patient's brain damage, taken about three years after infection. Note that the extent of the brain damage closely follows the course of the ventral branch of the uncinate fascicle. 


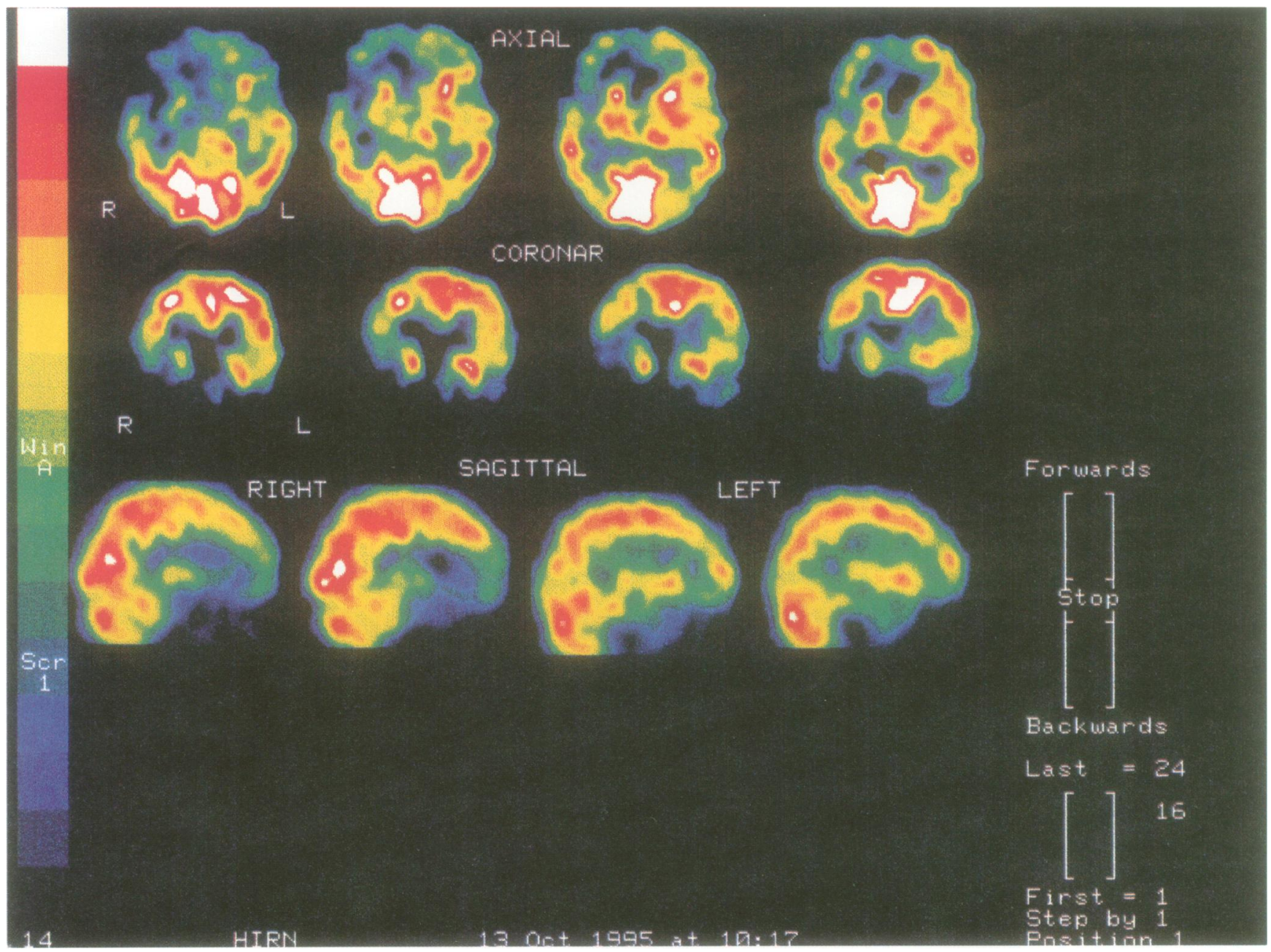

Figure $3{ }^{99 m} T c$ ECD SPECT sections, taken about three years after infection. Axial (top row), coronar (middle row), and right and left sagittal sections (bottom row) show the area of hypoperfusion in the right temporofrontal region.

frontotemporal brain damage seems possible (figs 1 and 2).

An ECD SPECT, performed in the initial phase of the disease, showed a pronounced hyperperfusion in the right frontotemporal area. After three months, a control SPECT still showed a moderate hyperperfusion in the same region, whereas a control, done three years later, showed an area of circumscribed hypoperfusion in the same location (fig 3).

Initial EEG recording showed a moderate but generalised slowing of the background activity as well as a theta/delta focus in the right temporoparietal region. Furthermore, intermittent epileptogenic activity characterised by single sharp waves, was recorded in the same area, without clinical evidence of epileptic seizures during her stay in hospital. After six months the EEG recording was completely normal.

Analysis of CSF showed a white cell count of $840 / 3$ cells and a protein level of $58 \mathrm{mg} \%$. The serological data showed positive findings of IgG and IgM antibodies to the herpes simplex type 1 virus. Values for CSF became normal six months after onset of the disease.

\section{NEUROPSYCHOLOGICAL EVALUATION}

Testing was performed two years after the infection. The neuropsychological tests and a summary of the results are listed in the table. They included tests of intelligence, attention, concentration, language, cognitive flexibility, and various forms of memory tests. Most of these tests have been used and described in detail in previous publications. ${ }^{2131516}$

The patient was alert and motivated. She took part in conversations, was socially well adjusted, and was able to interact in various ways. When instructed, she could remember to do something or to go to a certain place. In formal testing, she gained an IQ of 103 points, and her attention was in the normal range. In the Wechsler memory scale $R$ she was in the lower average range (general memory index 93 points). Other tests of verbal and non-verbal anterograde memory confirmed the impression of her normal to somewhat sub-average anterograde memory abilities. Her cognitive flexibility was below average.

\section{RETROGRADE MEMORY}

The patient described herself as lacking episodes of her personal past from several decades before her brain infection. We used the following tests to determine her performance level in the domains of retrograde episodic and semantic memory: the autobiographical memory interview (AMI) ${ }^{17}$ and the Crovitz form test ${ }^{4}$ were given to assess her 
Neuropsychological tests used and main test results

\begin{tabular}{|c|c|c|}
\hline Assessed function and test & Patient & $\begin{array}{l}\text { Normative data/ } \\
\text { Control subjects }\end{array}$ \\
\hline Intelligence & 103 & $100(\mathrm{SD} 15)$ \\
\hline \multicolumn{3}{|l|}{ Attention: } \\
\hline d2 Concentration-endurance test & $32 \%$ ile & $25 \%$ ile- $75 \%$ ile \\
\hline Trail making test, form $\mathrm{A}$ & $50 \%$ ile & $50 \%$ ile \\
\hline \multicolumn{3}{|l|}{ Language: } \\
\hline \multirow{2}{*}{\multicolumn{3}{|c|}{ Cognitive flexibility: }} \\
\hline & & \\
\hline FAS verbal fluency test & 16 & (cut off 17) \\
\hline Trail making test, form $\mathrm{B}$ & $83(25 \%$ ile $)$ & $50 \%$ ile \\
\hline \multirow{2}{*}{\multicolumn{3}{|c|}{ Learning and anterograde memory: }} \\
\hline & & \\
\hline Digit span forward & 6 & $5-6$ \\
\hline Digit span backward & 4 & $4-5$ \\
\hline Corsi block span forward & 5 & 5 \\
\hline Corsi block span backward & 4 & $4-5$ \\
\hline \multicolumn{3}{|l|}{ Wechsler memory scale-R } \\
\hline Attention/concentration index & 87 & 100 \\
\hline Verbal memory index & 99 & 100 \\
\hline Visual memory index & 88 & 100 \\
\hline General memory index & 93 & 100 \\
\hline Delayed recall & 86 & 100 \\
\hline \multicolumn{3}{|l|}{ Rey auditory verbal learning test } \\
\hline Trial 1 & 6 & $6 \cdot 4$ \\
\hline Trial 2 & 7 & $8 \cdot 2$ \\
\hline Trial 3 & 9 & $10 \cdot 2$ \\
\hline Trial 4 & 9 & $11 \cdot 1$ \\
\hline Trial 5 & 11 & $11 \cdot 6$ \\
\hline Distractor (list B) & 4 & $4 \cdot 6$ \\
\hline List 6 & 7 & $9 \cdot 9$ \\
\hline Delayed recall & 7 & $10 \cdot 2$ \\
\hline \multicolumn{3}{|l|}{ Rey complex figure } \\
\hline Copy & 35 & 35 \\
\hline 30 minute delay & 18 & $18 \cdot 8$ \\
\hline \multicolumn{3}{|l|}{ Retrograde memory: } \\
\hline \multicolumn{3}{|l|}{ Autobiographic memory interview } \\
\hline Personal semantic events & & \\
\hline $\begin{array}{l}\text { (childhood, adulthood, recent) } \\
\text { Autobiographical incidents }\end{array}$ & $14,12 \cdot 5,18$ & $21,20,21$ \\
\hline $\begin{array}{l}\text { Autobiographical incidents } \\
\text { (Childhood, adulthood, recent) }\end{array}$ & $1,2,7$ & $8,9,9$ \\
\hline Crovitz test $(10 \text { words per time period })^{4}$ & See fig. 4 & (3), \\
\hline Famous faces test $\dagger$ & $27 \%$ & $42 \%$ \\
\hline Semantic general knowledge test ${ }^{15,1 \mathrm{n}}$ & 71 & $\geqslant 92$ \\
\hline
\end{tabular}

For the Rey auditory verbal learning test and the Rey complex figure means are given after Spreen and Strauss:"; for the AMI the scores are given for a control subject of comparable age (taken from Weniger et al " ).

${ }^{\star}$ Although the number of remembered items is not atypical, the release from proactive interference (4, her last score) is below average.

tSee fig. 5 .

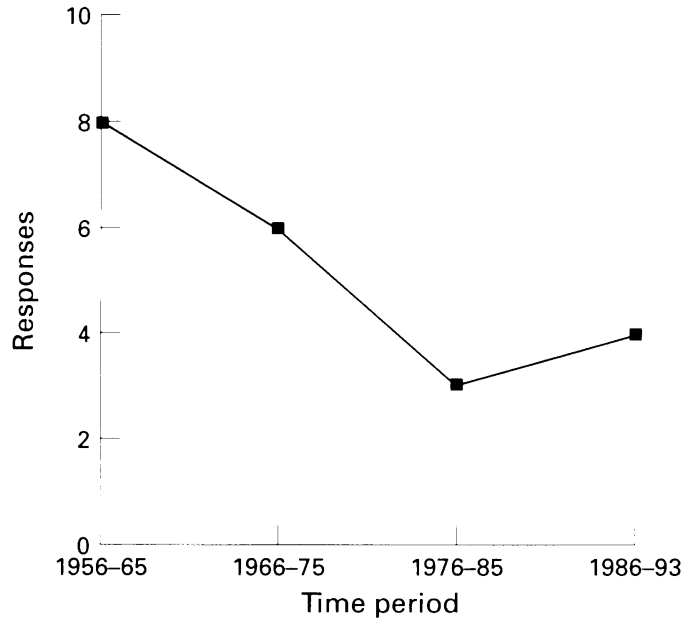

Figure 5 Famous faces test; 15 faces were presented/ period. Here, the patient was less impaired than in autobiographical memory, but nevertheless showed a time gradient which reflects the onset of the infection in 1993.

"Relate personally experienced life events from any time period evoked by each of the following words ...", and "Now estimate the date of its occurrence." The semantic general knowledge test uses 100 items of the kind "What is the name for the child of a cow?" or "What is the currency used in Switzerland?" It furthermore includes questions on geography, famous people, and animals, animal products, and attributes. The famous faces test contained per decade 15 portraits of famous people (sportspersons, politicians, actors, etc).

By contrast with her abilities to learn and remember new information, she had persistent and severe deficits in her old memory abilities. These were most prominent for her autobiographical past (fig 4), whereas her general knowledge, measured with a famous faces test (fig 5) and the world knowledge test (and also partly reflected by the semantic part of the autobiographical memory interview) was much less affected (table). istructured interview covering all epoch of a subject's life; it is subdivided into two parts covering the more general, semantic, and the personal events domains. In the Crovitz form test 10 high frequency nouns are administered and the patient is asked to describe personal experiences and unique episodes relating to each word. The instructions were:

\footnotetext{
Figure 4 Performance of the patient in the Crovitz test. Out of 10 possible responses/period, the patient was able to give only three or two for her earliest decades, and five for the period after the infection.
}

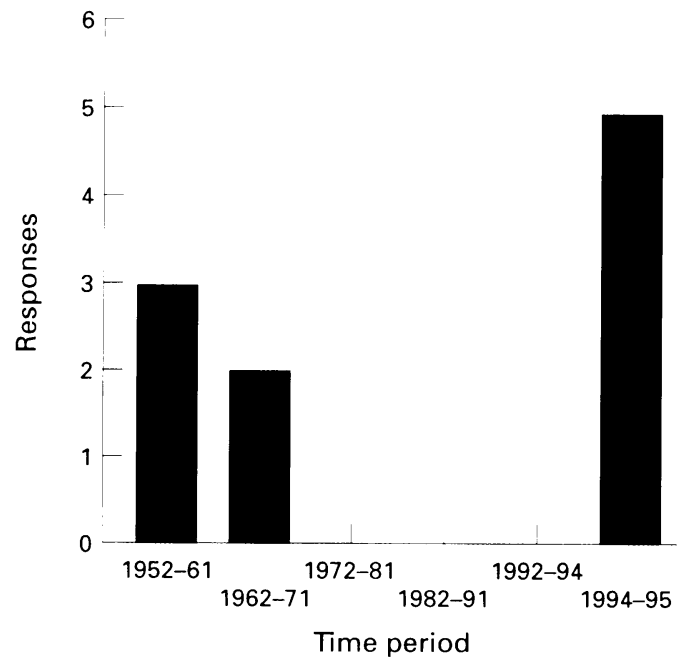

\section{Discussion}

Our patient is another in a series of several patients with a clear dissociation between anterograde and retrograde memory abilites. ${ }^{121320}$ She also fits into a series of patients with combined damage of predominantly temporopolar and inferolateral prefrontal regions and focal retrograde amnesia. ${ }^{13}$ (Her brain damage included the right medial temporal lobe as well, but we assume from comparing her case with previous ones 121113 that the lateral temporal lobe regions are critically implicated in retrograde amnesia.) Furthermore, she corresponds to the proposed scheme of hemispheric specific retrograde memory disturbances ${ }^{13}$ : her brain damage is predominantly right hemispheric and her memory disturbances are largely in the episodic memory domain. She also fits into the scheme proposed by Markowitsch ${ }^{13}$ for the occurrence of retrograde amnesia by having bilateral (although mainly right sided) brain damage. The aetiology of her brain damage is not unusual for patients with severe memory 
disturbances, ${ }^{2021}$ including focal retrograde amnesia. ${ }^{22}$

This case therefore combines all features of anatomicobehavioural interrelations for retrograde episodic amnesia, as predicted by Markowitsch's hypothesis. ${ }^{13}$ In addition, the overlap between episodic and semantic disturbances of old memories is in line with the assumption that these two memory systems have to be viewed more as a continuum than as sharply divisible entities: semantic information is generalised, repeated episodic information $^{23}$ and the generalised (episodic plus semantic) deficiency of brain damaged patients at the stage of memory encoding ${ }^{24}$ may hold for the level of information retrieval as well, although it may be more distinct in the non-damaged brain. ${ }^{13}$

The episodic memory system is most likely more sensitive to brain damage than the knowledge system: episodic information is unique, ${ }^{25}$ whereas semantic memories may derive from episodic ones through generalisation and repetition. ${ }^{23}$ Furthermore, episodic memories for ecphory probably need a synchronised activation of affect coding structures of the limbic system (amygdala). ${ }^{26}$ (Ecphory denotes the process by which retrieval cues interact with stored information so that an image or a representation of the information in question appears.)

The temporopolar orbitofrontal junction area will not be the locus of the engrams, but only a necessary mediator. ${ }^{13}$ Although we favour this region as the principal locus for memory ecphory, alternatively the disconnection between major prefrontal and posterior cortical regions may provide a basis for retrograde amnesia. Retrograde amnesia is certainly a multifaceted phenomenon which can accompany various kinds of diseases and which can occur after damage to quite divergent brain loci. ${ }^{12427}$

ROLE OF THE FRONTAL CORTEX IN RETRIEVAL

Results from studies in patients with selective prefrontal damage usually do not indicate significant retrieval deficits. Instead, only the active, effortful engagement in ecphorising information may be disturbed. ${ }^{28}$ Other features of mnemonic information processing which are altered after prefrontal damage include aspects of metamemory and memory for the temporal order of events. ${ }^{29}$ Furthermore, the prefrontal cortex is viewed as acting in monitoring or supervising environmental stimulation, or as applying strategies. ${ }^{29}$

All of these functions have, however, a closer affinity to the dorsolateral than to the orbitofrontal aspects of the frontal lobes. Damage to this region is assumed to induce changes in personality and emotional behaviour. ${ }^{2930}$ Brazzelli et al ${ }^{31}$ described a patient with bilateral frontal and some additional cingular and temporal damage who had severe amnesia, most likely including a failure to retrieve old memories although formal testing of retrograde memory could not be accomplished due to her incapacity to provide any kind of account. Recent ${ }^{15} \mathrm{O}$ PET studies pro- vide further evidence for a prefrontal involvement in verbal and pictorial episodic memory retrieval. ${ }^{32}$

In conclusion, the prefrontal cortex contributes to memory retrieval (or memory ecphory) both by providing the impetus or trigger for an active search of the engrams (stored at other places and most likely in a network-like fashion ${ }^{13}$ ) and by its capacity as a time sensitive organiser. As mentioned above, autobiographical memory is composed of personally relevant and temporal knowledge. The temporal structuring or ordering of information is apparently necessary for its successful ecphory and retrieval. Results from single cases with prefrontal damage strongly support this view. ${ }^{33} 34$ The patient's subnormal performance in all three tests on cognitive flexibility (and therefore a frontal lobe function) confirm the view, expressed by Kopelman, ${ }^{35}$ that test results in this domain are better predictors for retrograde memory performance than anterograde memory tests.

ROLE OF THE TEMPORAL CORTEX IN RETRIEVAL Penfield ${ }^{36}$ has elucidated many of the phenomena occurring during electrical stimulation of the temporal lobe. One of his findings was the appearance of what he called "psychical responses": reproductions of past personal experiences which he attributed to the (lateral) temporal cortex. Recently Fink et al ${ }^{26}$ similarly found with PET blood flow measurements a strongly increased activation in the anterior temporal regions in response to ecphorising autobiographical material. In summary, both case descriptions of epileptic patients with temporal lobe involvement and functional imaging data in normal human subjects indicate a role of lateral temporal portions in memory retrieval. The anterolateral temporal cortex most likely provides the connection to the posterior cortical centres of integration and therefore to the major storage places of the engrams. ${ }^{37}$

\section{EMOTION AND MEMORY}

Some studies point to emotional changes after brain damage. 153839 The recent speculation that the right hemisphere is principally engaged in episodic memory retrieval and the left in semantic memory retrieval, ${ }^{13}$ is in line with such a view as episodic memories are usually more emotional than semantic ones. Autobiographical information is probably represented in a more complex way than semantic information and needs an involvement from the left language representing hemisphere as well as from the right emotional one. The case of an adolescent patient with automatic but not consciously reflected memory retrieval demonstrates this point. ${ }^{40}$

It is not unlikely that the ecphory of episodic, but not of semantic, memory involves non-cortical limbic structures as well as the cortical ones, which primarily represent stored information. ${ }^{13}$ The basolateral limbic circuit, composed of portions of the prefrontal cortex, the amygdala, and the medial thalamus $^{38}$ constitutes a basis for a network impli- 
cated in emotional memory processing. ${ }^{4391}$ The region of the medial thalamus can furthermore be regarded as a central gating station for consciousness ${ }^{42}$ and therefore for the active, reflective processing, and associating of old memories. The mediodorsal nucleus not only projects to the prefrontal cortex, but especially to those portions of the temporal cortex as well which are implicated in the ecphory of old memories-namely, the temporal pole (area 38). ${ }^{37}$ On the corticocortical level, the temporopolar and the ventrolateral prefrontal areas are bidirectionally interconnected by the uncinate fascicle. ${ }^{13}$

Emotional flattening is a frequent concomitant in patients with retrograde amnesia, both of organic and psychogenic origin. ${ }^{1343}$ Taking all this evidence together, it is likely that damage to the temporofrontal junction areas may result in a blockade of access to stored engrams, particularly to those which require an emotional flavour for ecphory as well. ${ }^{25} 26$

\section{WHY IS THERE SUCCESSFUL RETRIEVAL OF} MEMORIES ACQUIRED AFTER BRAIN DAMAGE WITHOUT THE RIGHT TEMPOROFRONTAL JUNCTION AREA?

Patients with selective temporofrontal damage are still able to acquire new information long term after the insult and subsequently recall it long term. This recall must therefore occur via routes different from the damaged temporofrontal areas. The plasticity of the nervous system may lead to rewiring or rerouting of information acquired after the brain damage. Or the existence of hierarchically ordered recall systems can be assumed, similar to the models proposed for memory encoding after damage of relevant bottleneck structures. ${ }^{44}$ With respect to the differential retrieval of information acquired after brain damage (but not before brain damage), the additional requirement is that the process of information consolidation implies the immediate establishment of a retrieval path. In the intact brain this retrieval path would principally and primarily involve the temporofrontal junction areas. In the brain with damage to this region an immediate retrieval path would be established to other, intact structures, lower in hierarchy, and less accurate and precise in retrieval.

The proposal made by several authors implicitly or explicitly that the storage of the memory content is composed according to landmarks, may have the effect that after brain damage events which occurred before that landmark cannot be recalled, whereas those stored thereafter can be. ${ }^{4}$ This view might also be in accordance with Wolpaw's that brain damage may disrupt the association between memories due to the "missing link" (in the temporofrontal junction area) which is necessary for the organised triggering (in the frontal portion) and access (in the temporal portion) to the engrams. ${ }^{45}$

We are grateful to David Emmans for improvement of the language. The research of HJM is supported by the German Research Council (DFG).

1 Kapur N, Ellison D, Smith MP, Mcellan DL, Burrows EH.

Focal retrograde amnesia following bilateral temporal lobe pathology. Brain 1992;115:73-85.

2 Markowitsch HJ, Calabrese P, Liess J, Haupts M, Durwen HF, Gehlen W. Retrograde amnesia after traumatic injury of the temporo-frontal cortex. $\mathcal{F}$ Neurol Neurosurg sychiatry 1993;56:988-92.

3 Della Sala S, Laiacona $M$, Spinnler $H$, Trivelli $C$. Autobiographical recollection and frontal damage. Neuropsychologia 1993;31:823-39.

4 Hodges JR, McCarthy RA. Autobiographical amnesia resulting from bilateral paramedian thalamic infarction. Brain 1993;116:921-40.

5 Hodges JR, McCarthy RA. Loss of remote memory: a cognitive neuropsychological perspective. Curr Opin Neurobiol 1995;5:178-83.

6 Kapur N. Focal retrograde amnesia in neurological disease: a critical review. Cortex 1993;29:217-34.

7 Kopelman MD. The neuropsychology of remote memory. In: Boller F, Grafman J, eds. Handbook of neuropsychology. Vol 8. Amsterdam: Elsevier, 1993:215-38.

8 Shallice T, Fletcher P, Frith CD, Grasby P, Frackowiak RSJ, Dolan RJ. Brain regions associated with acquisition and retrieval of verbal episodic memory. Nature 1994 368:633-5.

9 Tulving E, Kapur S, Markowitsch HJ, Craik G, Habib R Houle $S$. Neuroanatomical correlates of retrieval in episodic memory: auditory sentence recognition. Proc Natl Acad Sci USA 1994;91:2012-5.

10 Tulving E, Kapur S, Craik FIM, Moscovitch M, Houle S. Hemispheric encoding/retrieval asymmetry in episodic memory: positron emission tomography findings. Proc Natl Acad Sci USA 1994;91:2016-20.

11 Markowitsch HJ. Anatomical basis of memory disorders. In: Gazzaniga MS, ed. The cognitive neurosciences. Cambridge, MA: MIT Press, 1995:665-79.

12 Markowitsch HJ, Calabrese P, Haupts M, Durwen HF Liess J, Gehlen W. Searching for the anatomical basis of retrograde amnesia. F Clin Exp Neuropsychol 1993;15: retrograde

13 Markowitsch $H J$. Which brain regions are critically involved in the retrieval of old episodic memory? Brain Res Rev 1995;21:117-27.

14 Tulving E. Organization of memory: quo vadis? In: Gazzaniga MS, ed. The cognitive neurosciences. Cambridge, MA: MIT Press, 1995:839-47.

15 Cramon DY von, Markowitsch HJ, Schuri U. The possible contribution of the septal region to memory. Neuropsychologia 1993;31:1159-80.

16 Markowitsch HJ, von Cramon DY, Schuri U. Mnestic performance profile of a bilateral diencephalic-damaged case with preserved intelligence and severe amnesic disturbances. $₹$ Clin Exp Neuropsychol 1993;15:627-52

17 Kopelman MD, Wilson BA, Baddeley AD. The autobiographical memory interview: a new assessment of autobiographical and personal semantic memory in amnesic patients. 7 Clin Exp Neuropsychol 1990;11:724-44.

18 Spreen O, Strauss E. A compendium of neuropsychological tests. Oxford: Oxford University Press, 1991.

19 Weniger G, Markowitsch HJ, Irle E. Anterograde and retrograde mnemonic deficits after unilateral damage of neostriatal, ventral striatal, and basal forebrain structures. Neurocase 1995;1:231-8.

20 Kapur N, Barker S, Burrows EH, et al. Herpes simplex encephalitis: long term magnetic resonance imaging and neuropsychological profile. $₹$ Neurol Neurosurg Psychiatry 1994;57:1334-2.

21 Damasio AR, Eslinger PJ, Damasio H, Van Hoesen GW, Cornell S. Multimodal amnesic syndrome following bilateral temporal and basal forebrain damage. Arch Neurol 1985;42:252-9.

22 Eslinger PJ, Easton A, Grattan LM, Van Hoesen GW. Distinctive forms of partial retrograde amnesia after asymmetric temporal lobe lesions. Possible role of the asymmetric temporal lobe lesions. Possible role of the occipitotempora

23 Hodges JR. Semantic memory and frontal executive function during transient global amnesia. $\mathcal{F}$ Neurol Neurosurg Psychiatry 1994;57:605-8.

24 Verfaellie M, Cermak LS. Acquisition of generic memory in amnesia. Cortex 1994;30:293-303.

25 Damasio AR. Category-related recognition defects as a clue to the neural substrates of knowledge. TINS 1990;13: 95-8.

26 Fink GR, Markowitsch HJ, Reinkemeier M, Kessler J, Heiss W-D. Cerebral representation of one's own past: neural networks involved in autobiographical memory. $\mathcal{f}$ Neurosci 1996;16:4275-82.

27 Ogden JA. Visual object agnosia, prosopagnosia, achromatopsia, loss of visual imagery, and autobiographical amnesia following recovery from cortical blindness: case MH Neuropsychologia 1993;31:571-89.

28 Jetter W, Poser U, Freeman RB Jr., Markowitsch HJ. A verbal long term memory deficit in frontal lobe damaged patients. Cortex 1986;22:229-42.

29 Röhrenbach C, Markowitsch HJ. Störungen im Präfrontalbereich. In: Markowitsch HJ, ed. Enzyklopädie der Psychologie, Themenbereich C, Serie I, Band 2: Klinische Neuropsychologie (in press). Göttingen: Hogrefe, 1996.

30 George MS, Ketter TA, Gill DS, et al. Brain regions involved in recognizing facial emotion or identity: an oxygen-15 PET study. $\mathcal{f}$ Neuropsychiatry Clin Neurosci 1993;5:384-94.

31 Brazzelli M, Colombo, N, Della Sala S, Spinnler H. Spared and impaired cognitive abilities after bilateral frontal damage. Cortex 1994;30:27-51. 
32 Tulving E, Markowitsch HJ, Craik FIM, Habib R, Houle $S$. Novelty and familiarity activations in PET studies of memory enco

33 Dall'Ora P, Della Sala S, Spinnler H. Autobiographical memory. Its impairment in amnesic syndromes. Cortex memory. Its impairn.

34 Della Sala S, Laiacona $M$, Spinnler $H$, Trivelli C. Autobiographical recollection and frontal damage. Neuropsychologia 1993;31:823-39.

35 Kopelman MD. The autobiographical memory interview (AMI) in organic and psychogenic amnesia. Memory 1994;2:211-35.

36 Penfield W. The mystery of the mind. Princeton, NJ: Princeton University Press, 1975.

37 Markowitsch HJ, Emmans D, Irle E, Streicher $\mathbf{M}$, Preilowski B. Cortical and subcortical afferent connections of the primate's temporal pole. A study using rhesus monkeys, squirrel monkeys, and marmosets. $尹$ f Comp Neurol 1985;242:425-58.

38 Sarter M, Markowitsch HJ. The amygdala's role in human mnemonic processing. Cortex 1985;21:7-24.
39 Markowitsch HJ, Calabrese P, Würker M, et al. The amygdala's contribution to memory-a PET-study on two patients with Urbach-Wiethe disease. Neuroreport 1994; 5:1349-52.

40 Vargha-Khadem F, Isaacs E, Mishkin M. Agnosia, alexia and a remarkable form of amnesia in an adolescent boy. and a remarkable form of

41 Swartz BE, Halgren E, Fuster JM, Simpkins F, Gee M, Mandelkern M. Cortical metabolic activation in human Mandelkern M. Cortical metabolic activation in humans

42 Bogen JE. On the neurophysiology of consciousness: I. An overview. Consciousness and Cognition 1995;4:52-62.

43 Wechsler AF. The effect of organic brain disease on recall of emotionally charged versus neutral narrative texts. Neurology 1973;23:130-5.

44 Markowitsch HJ. Individual differences in memory performance and the brain. In: Markowitsch HJ, ed. Information processing by the brain. Toronto: Huber, 1988:125-48.

45 Wolpaw JR. The aetiology of retrograde amnesia. Lancet 1971;ii:356-8.

\section{NEUROLOGY IN LITERATURE}

\section{Doctors' writing, and writings}

The quality of doctors' writing has long been the object of writers' humour. I suspect that doctors, just as novelists, can suffer from writer's block although in the case of the medical profession more perhaps from lack of time rather than from a failure of inspiration. Which explanation applies to Ovid Vere, in Heart and science, is not entirely clear. Thomas Mann's encyclopedia is one I have tried to emulate but as yet with no success in finding a willing publisher!

Samuel fohnson, 1779, Lives of the English poetsDryden

It is a rare kind of giblet porridge, made of the giblets of a couple of young geese, stodged full of meteors, orbs, spheres, track, hideous draughts, dark characters, white forms, and radiant lights, designed not only to please appetite, and indulge luxury; but it is also physical, being an approved medicine to purge choler: for it is propounded by Morena, as a receipt to cure their fathers of their choleric humours: and were it written in characters as barbarous as the words, might very well pass for a doctor's bill.

Gustave Flaubert, 1856-7, Madam Bovary

Emma looked at him and shrugged her shoulders. Why hadn't she at any rate one of those silent, earnest husbands who work at their books all night-and end up, by the time that rheumatism sets in at sixty, wearing a string of decorations on their ill-fitting dress-coats! She would have liked this name of Bovary, that was hers, to be famous, on view at the book-shops, always cropping up in the papers, known all over France. But Charles had no ambition.

Wilkie Collins, 1883, Heart and science

His restless hand unlocked a drawer, and took out a manuscript work on medicine of his own writing. "Surely," he thought, "I may finish a chapter, before I go to sea tomorrow?"

Thomas Mann, 1924, The magic mountain

Famous European specialists, physicians, psychologists, and economists will share in the composition of this encyclopedia of suffering, and the general editorial bureau at Lugano will act as the reservoir to collect all the articles which shall flow into it ... This great work will not neglect the belletrist in so far as he deals with human suffering: a volume is projected which shall contain a compilation and brief analysis of such masterpieces of the world's literature as come into question depicting one or other kind of conflict-for the consolation and instruction of the suffering. G D PERKIN Regional Neurosciences Centre Charing Cross Hospital, Fulham Palace Road London W6 8RF, UK 